\title{
Value of Combination of Standard Axial and Thin-Section Coronal Diffusion-weighted Imaging in Diagnosis of Acute Brainstem Infarction
}

\author{
Nashwan I. Khaleel ${ }^{1}$, Muna A. G. Zghair ${ }^{2}$, Qays A. Hassan ${ }^{3^{*}}$ \\ ${ }^{1}$ Department of Radiology, Al-Yarmook Teaching Hospital, Baghdad, Iraq; ${ }^{2}$ Division of Radiology, Department of Medicine, \\ College of Medicine, Al-Mustansiriyah University, Baghdad, Iraq; ${ }^{3}$ Division of Radiology, Department of Surgery, Al-Kindy \\ College of Medicine, University of Baghdad, Baghdad, Iraq
}

\begin{abstract}
Citation: Khaleel NI, Zghair MAG, Hassan QA. Value of Combination of Standard Axial and Thin-Section Value Diffusion-weighted Imaging in Diagnosis of Acut Brainstem Infarction. Open Access Maced J Med Sci. $2019 \quad$ Jul $\quad 30 ; \quad$ 7(14):2287-2291 https://doi.org/10.3889/oamjms.2019.336 Keywords: Brainstem; Axial; Coronal; DWI; Stroke

*Correspondence: Oays A. Hassan Division Correspondence: Qays A. Hassan. Division of Medicine, University of Baghdad, Baghdad, Iraq. E-mail qtimeme@yahoo.com

Received: 28-Mar-2019; Revised: 04-Jun-2019; Received: 28-Mar-2019, Revised: 04-Jun-20 Copyright: ๑) 2019 Nashwan I. Khaleel, Muna AG. Zghair, Qays A. Hassan. This is an open-access article Attribution-NonCommercial 4.0 International License (CC BY-NC 4.0)

Funding: This research did not receive any financial

Competing Interests: The authors have declared that no competing interests exist
\end{abstract}

\begin{abstract}
AIM: To determine the value of the combination of thin-section $3 \mathrm{~mm}$ coronal and standard axial DWI and their impact in facilitating the diagnosis of acute brainstem infarction.

METHODS: A cross-sectional study conducted from the 1st of April 2017 to the end of February 2018 on 100 consecutive patients (66\% were male, and $34 \%$ were female) with isolated acute ischemic infarction in the brainstem. The abnormal MRI findings concerning the ischemic lesions were interpreted on standard axial 5 $\mathrm{mm}$ and thin-section coronal $3 \mathrm{~mm}$ DWI.

RESULTS: The mean age of the studied group was $69.2 \pm 4.3$ for male and $72.3 \pm 2.5$ years. The standard axia DWI can diagnose $20 \%, 6.7 \%$ and $6.7 \%$ of the infarctions in midbrain, pons and medulla oblongata respectively, while both axial and thin coronal sections together can diagnose $80 \%$ of midbrain infarctions, $93.3 \%$ of pons infarctions and $93.3 \%$ of medulla oblongata infarctions. Furthermore, the thin section coronal $3 \mathrm{~mm}$ section can diagnose very smaller ischemic lesion volume in comparison to the standard axial $5 \mathrm{~mm}$ section $\left(3.4 \pm 0.45 / \mathrm{cm}^{3}\right.$ versus $4.6 \pm 0.23 / \mathrm{cm}^{3}, \mathrm{P}<0.001$ )

CONCLUSION: The addition of thin-section coronal DWI can facilitate the detection of brainstem ischemic
\end{abstract} lesions. We suggest its inclusion in the stroke MRI protocol.

\section{Introduction}

The detection of acute brainstem ischemic infarction remains a challenge to both neurologist and radiologist in spite of the revolution of the imaging techniques. This type of infarction forms just about $10 \%$ of all acute ischemic strokes [1]. Pons is the most frequent site, followed by the medulla oblongata, and the midbrain [2]. Cranial nerve palsies, sensory loss, motor hemiparesis, vertigo, ataxia, and other specific brainstem syndromes represent the variable clinical presentation of this sort of infarction [1]. Vertebral arteries, basilar artery, anterior spinal artery, anterior inferior cerebellar arteries, posterior inferior cerebellar arteries, posterior cerebral arteries, and superior cerebellar arteries compromise the chief arterial supply of the brainstem [3]. Most frequent causes of brainstem infarction include large vessel disease of the vertebral arteries or basilar artery, small vessel disease of small perforating arteries, and cardiac thromboembolism [1]. For early diagnosis of brain small ischemic lesions, Diffusion-weighted imaging (DWI) regarded the highly sensitive method [4]. Accordingly, DWI becomes a good method to recognise and achieve the detection of acute brainstem infarction [5]. However, false-negative DWI is higher in the infratentorial due to the limited spatial resolution with standard axial $5 \mathrm{~mm}$ DWI [6], [7]. 
In this study, we attempted to assess the added benefit of combined standard axial and additional thin-section $3 \mathrm{~mm}$ coronal DWI for the discovery of brainstem infarction.

\section{Patients and Methods}

\section{Study design and setting}

All patients with isolated acute ischemic infarction in the brainstem diagnosed by MRI in our hospital from the $1^{\text {st }}$ of April 2016 to the end of February 2018 were included in this prospective cross-sectional study.

\section{MRI protocols}

Magnetic resonance imaging was performed on 3-Tesla MR system (Achieva, Phillips, Holland). Diffusion-weighted imaging using axial standard $5 \mathrm{~mm}$ section and thin coronal section $3 \mathrm{~mm}$, in addition to T1, T2, FLAIR and ADC sequences were performed on each patient. Table 1 exhibited the parameters of applied DWI sequences.

Table 1: Weighting imaging applied at the department of MR scanner

\begin{tabular}{llc}
\hline DWI sequence & Parameters & 3-T Philips \\
Achieva
\end{tabular}

\section{Images interpretation}

The abnormal hyperintense signals in the brainstem were analysed on standard axial and thinsection coronal DWI. According to their site, the detected lesions were classified into (1) midbrain lesions; (2) pons lesions; and (3) medulla oblongata lesions. The discovery of ischemic lesions in standard axial and thin-section coronal DWI was independently assessed by two efficient specialized radiologists with more than 10 years' experience in brain imaging who were blinded to the clinical data and recognized as (1) better depiction on axial DWI; (2) better depiction on combined axial and thin section coronal DWI. Equivocal cases were reassessed by both readers and discussed until a unique decision was achieved. The size of the ischemic lesion was calculated on DWI by manually drawn ROI. The volume $\left(\mathrm{cm}^{3}\right)$ of each detected lesion was calculated by summation of the lesion areas $\left(\mathrm{cm}^{2}\right)$ on each section and multiplied by the slice thickness and inter-slice gap. This was achieved by the use of Radiant Dicom Viewer.

\section{Ethical concern}

Approval by the local institutional review board was obtained before the study commencement. The purpose and procedures explained to all participants and were given the right to participate or not; verbal consent was taken with the reassurance that interprets gained will be kept confidentially and not be used for another research object.

\section{Statistical analysis}

All patients' data entered using computerised statistical software; Statistical Package for Social Sciences (SPSS) version 21 was used. Descriptive statistics presented as (mean \pm standard deviation) and frequencies as percentages. Kolmogorov Smirnov analysis verified the normality of the data set. Multiple contingency tables conducted and appropriate statistical tests performed, Chi-square test used for categorical variables. In all statistical analysis, level of significance ( $P$-value) set at $\leq .05$, and the result presented as tables.

\section{Results}

One hundred patients with isolated brainstem ischemia were enrolled in the current study. Males constitute $66 \%$ of the study sample, while females constitute $34 \%$ with a male to female ratio $1.9: 1$. The mean age of the studied group was $69.2 \pm 4.3$ for males and $72.3 \pm 2.5$ years for females. The main age group studied was $60-69$ years $(40 \%)$ then $\geq 70$ years $(30 \%)$, then $50-59$ years (16\%) and the last group was $40-49$ years $(14 \%)$.

Table 2: Distribution of brainstem infarction site according to the section of DWI sequence

\begin{tabular}{lcccc}
\hline & Midbrain & Pons & $\begin{array}{c}\text { Medulla } \\
\text { oblongata }\end{array}$ & \\
\cline { 2 - 5 } & No. (\%) & No. (\%) & No. (\%) & $P$ \\
\hline $\begin{array}{l}\text { Axial standard DWI section } \\
\text { Both thin section coronal and standard }\end{array}$ & $8(20.0)$ & $4(6.7)$ & $2(6.7)$ & \\
$\begin{array}{l}\text { axial section DWI } \\
\text { Total }\end{array}$ & $56(93.3)$ & $28(93.3)$ & 0.840 \\
\hline
\end{tabular}

We identified $60(60 \%)$ of the brainstem ischemia were located in the pons, $30(30 \%)$ of the ischemia in the medulla oblongata and $10(10 \%)$ in the midbrain.

Regarding the gender, it was found about 6 $(60 \%)$ of the midbrain infarction were in male, and 4 $(40 \%)$ were in female, same per cent were found for 
pons $60 \%$ for male and $40 \%$ for female, while $80 \%$ of the infarctions located in medulla oblongata were in males and the rest $20 \%$ were in females.
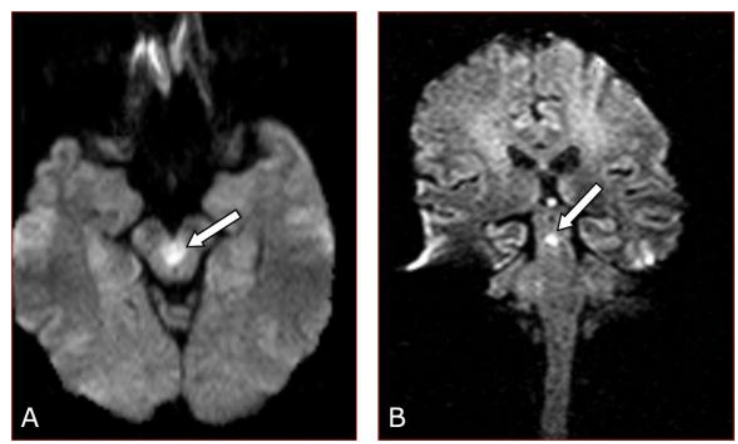

Figure 1: Acute midline midbrain infarction in a patient aged 60 years suffer from ataxia and vision problems; A) Standard axialsection $5 \mathrm{~mm} \mathrm{DWl}$ B) Thin-section coronal $3 \mathrm{~mm} \mathrm{DWI}$. The lesion is more delineated in the latter sequence image

Our results show that $92.0 \%$ of the lesions were easily seen by both axial section and thin coronal section sequence of DWI, and only $8 \%$ can be seen easily by axial section DWI.
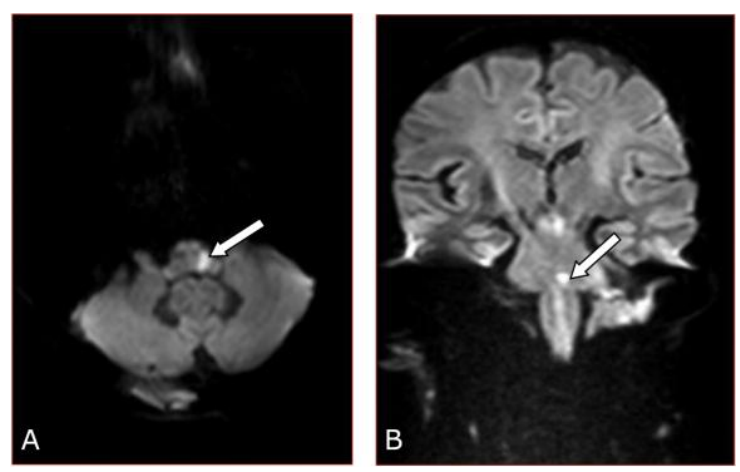

Figure 2: Acute left pons infarction in a patient aged 70 years suffered from dysphasia; A) Standard axial-section $5 \mathrm{~mm} \mathrm{DWl;} \mathrm{B)}$ Thin-section coronal $3 \mathrm{~mm}$ DWI. The lesion is more delineated in the latter sequence image

The standard axial DWI can diagnose $20 \%$, $6.7 \%$ and $6.7 \%$ of the infarctions in midbrain, pons and medulla oblongata respectively, while both axial and thin coronal sections together can diagnose $80 \%$ of midbrain infarctions, $93.3 \%$ of pons infarctions and $93.3 \%$ of medulla oblongata infarctions (Table 2) (Figures 1, 2, and 3).
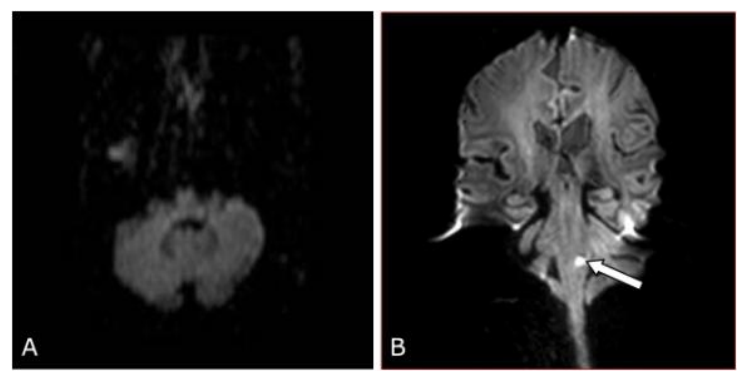

Figure 3: Acute ischemic infarction in the left medulla oblongata in a patient aged 62 years suffered from hemiplegia; A) On standard axial $5 \mathrm{~mm} \mathrm{DWI}$, the ischemic lesion is not visible; B) On thinsection coronal $3 \mathrm{~mm} \mathrm{DWI}$, the ischemic lesion is delineated
There was a non-significant association $(P=$ 0.840 ) between the sequence of DWI and the site of the brainstem infarction where pons and medulla oblongata infarctions were seen better by combining of axial and thin coronal section of DWI sequence.

Highly significant association were found between the sequence of DWI and detection of the ischemic lesion were thin coronal section can diagnose very smaller ischemic lesion volume in comparison to the standard axial $5 \mathrm{~mm}$ section $(3.4 \pm$ $0.45 / \mathrm{cm}^{3}$ versus $4.6 \pm 0.23 / \mathrm{cm}^{3}, P<0.001$ ) (Table 3).

Table 3: Correlation and evaluation of ischemic lesion volume to the section of the DWI sequence

\begin{tabular}{lcc}
\hline & Mean ischemic lesion volume $/ \mathrm{cm}^{3}$ & $P$ \\
\hline Standard axial section DWI & $4.6 \pm 0.23$ & \\
Thin section coronal DWI & $3.4 \pm 0.45$ & $<0.001$ \\
\hline
\end{tabular}

\section{Discussion}

Brainstem infarctions are usually small in size, round or oval, and demarcated from the adjacent tissue. Also, the tissue mainly consists of white matter and devoid of cerebrospinal fluid space. The heterogeneity of the tissue and the presence of CSF space in the tissue can affect the MRI indices [8]. Tiny ischemic lesion in the brainstem may cause important clinical symptoms due to its relatively small size and hardly arranged tissue composition. However, the diagnosis of brainstem infarction is incomplete if depend only on clinical bases [9]. Wardlaw et al., [4] mentioned that the gold standard for detection of acute ischemic stroke is the diffusion-weighted imaging. But DWI may fail to find the pathology of the very tiny brainstem ischemic lesion particularly located in the posterior fossa [6], [10], [11]. Besides, some studies establish high false-negative results particularly within the first $24 \mathrm{~h}$ [6], [12], [13]. To overcome these limitations, additional thin-section coronal DWI of the infratentorial has been proposed [14], [15].

The current study was showing regarding the gender that male was more than female represented about 2 / 3 of cases. Moreover, the mean age of the male was $69.2 \pm 4.3$ years, and the female were 72.3 \pm 2.5 . This is in agreement with Irimie CA et al., [15] which demonstrate the gender distribution of ischemic stroke risk factors in psychiatry and neurology hospital who mentioned similar findings.

In a study done by Felfeli $P$ et al., [16] in 2017, only $2 \%$ of cases of acute brainstem infarction were detected by thin-section coronal DWI. Our study showed that $(92.0 \%)$ of patients were easily seen by both sequence (standard axial and added thin coronal section) of DWI, and only (8\%) can be easily seen by 
axial DWI section. Although the detection rate still better by combining standard axial section and thin coronal section DWI sequences but from the volumetric statistical point of view lesions are seen more obvious by thin coronal section in which (mean ischemic lesion volume $/ \mathrm{cm}^{3}$ ) were $3.4 \pm 0.45$ compared to that measurement by standard axial section $4.6 \pm 0.23$ with $P$ value of $<0.001$ which is statistically significant.

Misdiagnosis of small brainstem ischemic lesion in an individual patient may have dangerous outcomes such as recurrent stroke and death [17]. Furthermore, very small ischemic lesions in the brainstem were much better identifiable on thinsection coronal DWI in comparison to standard axial section DWI from the volumetric statistical point. Therefore, for the discovery of very small brainstem infarctions, thin-section coronal DWI might be of help.

The current study results showed that combined coronal and axial DWI could better demonstrate the ischemic lesion of the midbrain in 8 $(80 \%)$, of the pons in $56(93.3 \%)$ and the medulla oblongata in $28(93.3 \%)$. These values were more than that found in Felfeli $P$ et al., [16] study where the thin-section coronal DWI was better identified the ischemic lesions of the midbrain in $8.6 \%$, of the pons in $45.7 \%$, and the medulla oblongata in $45.7 \%$.

Highly significant association were found between the sequence of DWI in the study (thin coronal and standard axial sections) and ischemic size lesion $(P<0.001)$.

The results of this study would clarify the opportunity of early identification of brainstem ischemia if we added thin-section coronal DWI to the stroke MRI protocol. This point is of high clinical consequence for two reasons. First, as the diagnosis of brainstem infarction is imperfect if based exclusively on clinical grounds, this early and clear identification of ischemia allows easy differentiation of similar clinical syndromes. Second, quick detection of brainstem infarction could be a significant clue to a basilar thrombosis at an early stage that would manipulate additional therapeutic management.

Two main limitations associated with this study. First, this is a single institutional study. Second, a consensus reading instead of following up was the main determinant of the acute ischemic lesions.

In conclusion, the combination of both coronal and axial DWI section can be done from 2 points of views. First, the further information which can achieve by adding thin-section coronal DWI sequence is additive value especially when some of the lesions cannot be seen by standard axial section DWI sequence in the presence of strong clinical suspicion. Second, according to statistical analysis, the detection rate is superior in combined standard axial and thin section coronal DWI sequence, but using coronal thinsection DWI would be more useful from the volumetric point of analysis. Accordingly, we advise the inclusion of thin-section coronal DWI sequence in standard stroke MRI protocols for patients with suspected stroke in the posterior fossa, because this combination can probably facilitate the discovery of brainstem infarction.

\section{References}

1. Ortiz de Mendivil A, Alcalá-Galiano A, Ochoa M, et al. Brainstem stroke: Anatomy, clinical and radiological findings. Semin Ultrasound CT MR. 2013; 34:131-141.

https://doi.org/10.1053/j.sult.2013.01.004 PMid:23522778

2. Burger KM, Tuhrim S, Naidich TP. Brainstem vascular stroke anatomy. Neuroimaging Clin N Am. 2005; 15:297-324. https://doi.org/10.1016/i.nic.2005.05.005 PMid:16198942

3. Tatu L, Moulin T, Bogousslavsky J, et al. Arterial territories of human brain Brainstem and cerebellum. Neurology. 1996; 47:1125-1135. https://doi.org/10.1212/WNL.47.5.1125 PMid:8909417

4. Wardlaw JM, Armitage P, Dennis MS, et al. The use of diffusionweighted magnetic resonance imaging to identify infarctions in patients with minor strokes. J Stroke Cerebrovas Dis. 2000; 9:70-

75. https://doi.org/10.1053/jscd.2000.0090070 PMid:17895199

5. Toi $\mathrm{H}$, Uno M, Harada M, et al. Diagnosis of acute brain-stem infarcts using diffusion-weighed MRI. Neuroradiology. 2003; 45:352-356. https://doi.org/10.1007/s00234-002-0897-5 PMid:12712305

6. Oppenheim C, Stanescu R, Dormont D, et al. False-negative diffusion-weighted MR findings in acute ischemic stroke. AJNR Am J Neuroradiol. 2000; 21:1434-1440.

7. Entwisle T, Perchyonok Y, Fitt G. Thin section magnetic resonance diffusion-weighted imaging in the detection of acute infratentorial stroke. J Med Imaging Radiat Oncol. 2016; 60:616623. https://doi.org/10.1111/1754-9485.12490 PMid:27324575

8. Ono $\mathrm{H}$, Nishijima $\mathrm{Y}$, Adachi $\mathrm{N}$, et al. Improved brain MRI indices in the acute brain stem infarct sites treated with hydroxyl radical scavengers, Edaravone and hydrogen, as compared to Edaravone alone. A non-controlled study. Med gas res. 2011; $1: 12$. https://doi.org/10.1186/2045-9912-1-12 PMid:22146068 PMCid:PMC3231971

9. Gerraty RP, Parsons MW, Barber PA, et al. Examining the lacunar hypothesis with diffusion and perfusion magnetic resonance imaging. Stroke 2002; 33:2019-2024. https://doi.org/10.1161/01.STR.0000020841.74704.5B PMid:12154256

10. Etgen $\mathrm{T}$, Gräfin von Einsiedel $\mathrm{H}$, et al. Detection of Acute Brainstem Infarction by Using DWI/MRI. Eur Neurol 2004; 52:145150. https://doi.org/10.1159/000081623 PMid:15492483

11. Sylaja PN, Coutts SB, Krol A, et al. VISION Study Group. When to expect negative diffusion-weighted images in stroke and transient ischemic attack. Stroke. 2008; 39:1898-1900. https://doi.org/10.1161/STROKEAHA.107.497453 PMid:18420957

12. Kuker W, Weise J, Krapf $H$, et al. MRI characteristics of acute and subacute brainstem and thalamic infarctions: Value of T2- and diffusion-weighted sequences. J Neurol. 2002; 249:33-42. https://doi.org/10.1007/PL00007845 PMid:11954866

13. Narisawa A, Shamoto $H$, Shimizu $H$, et al. Diffusion-weighted magnetic resonance imaging (MRI) in acute brain stem infarction No To Shinkei 2001; 53:1021-1026.

14. Sorimachi T, ItoY, Morita K, et al. Thin-section diffusionweighted imaging of the infratentorial in patients with acute cerebral ischemia without apparent lesion on conventional 
diffusion-weighted-imaging. Neurologia Medico Chirurgica. 2008; 48:108-13. https://doi.org/10.2176/nmc.48.108 PMid:18362456

15. Irimie CA, Minea DI, Nedelcu L, et al. Gender distribution of risk factors in ischemic stroke in the hospital of psychiatry and neurology from Brasov. Bulletin of the Transilvania University of Braşov Series VI: Medical Sciences. 2014; 7:53-60.

16. Felfeli $\mathrm{P}, \mathrm{Wenz} \mathrm{H}, \mathrm{Al}$-Zghloul $\mathrm{M}$, et al. Combination of standard axial and thin-section coronal diffusion-weighted imaging facilitates the diagnosis of brainstem infarction. Brain behav. 2017; 7:e00666. https://doi.org/10.1002/brb3.666 PMid:28413710

PMCid:PMC5390842

17. Kuruvilla A, Bhattacharya $P$, Rajamani $K$, et al. Factors associated with misdiagnosis of acute stroke in young adults. $\mathrm{J}$ Stroke Cerebrovas Dis. 2011; 20:523-527.

https://doi.org/10.1016/j.jstrokecerebrovasdis.2010.03.005

PMid:20719534 